\title{
ИННОВАЦИОННЫЕ НАПРАВЛЕНИЯ РАЗВИТИЯ ГОСУДАРСТВЕННОГО НАЛОГОВОГО МЕНЕДЖМЕНТА В ЦЕЛЯХ ОБЕСПЕЧЕНИЯ УСТОЙЧИВОГО ГЛОБАЛЬНОГО РАЗВИТИЯ РОССИЙСКОЙ ФЕДЕРАЦИИ
}

В статье обоснована необходимость преобразований и определения новых подходов к осуиествлению государственного налогового менеджмента. В качестве основных приоритетных задач налогового менеджиента авторами предложены ликвидация бедности в отдельных субъектах РФ и сокращение уровня дифференциачии доходов населения. Разработаны следуюиие инновационные инструменты налогового менеджмента: необлагаемый налоговый минимум (создание порогового уровня доходов, при котором малообеспеченные слои населения будут освобожсены от уплаты налогов, позволит минимизировать нагрузку), а также налоговые льготы. В результате реализации предложенных автором направлений представляется возможным нивелировать социально-экономическое неравенство на мезоуровне.

Ключевые слова: налоги, налоговый менеджмент, налогово-бюджетная политика государства; сочиально-экономическая дифференциачия; процессы глобализации.

\section{Tatyana Kulagovskaya, Ekaterina Bilous \\ THE INNOVATIVE DIRECTIONS OF DEVELOPMENT OF THE STATE TAX MANAGEMENT FOR ENSURING SUSTAINABLE GLOBAL DEVELOPMENT OF THE RUSSIAN FEDERATION}

In article need of transformations and definition of new approaches to implementation of the state tax management is proved. As the main priority objectives of tax management by authors are offered elimination of poverty in certain territorial subjects of the Russian Federation and reduction of level of differentiation of income of the population. The following innovative instruments of tax management: a free tax minimum (creation of threshold level of income during which lower-income strata will be exempted from payment of taxes, will allow to minimize loading) and also tax benefits are developed. As a result of realization of the directions offered by the author it is obviously possible to level social and economic inequality at the mesolevel.

Key words: taxes, tax management, tax and budgetary policy of the state; social and economic differentiation; globalization processes.

Bведениe / Introduction. Государственный налоговый менеджмент на современном этапе развития экономики требует значительных преобразований и определения новых подходов к его осуществлению.

Налоги занимают немаловажное место среди множества экономических рычагов, при помощи которых государство воздействует на рыночную экономику. В условиях рыночных отношений налоговая система является одним из важнейших экономических регуляторов, основой финансово-кредитного механизма государственного регулирования экономики. Государство широко использует налоговую политику в качестве определенного регулятора воздействия на негативные явления рынка. Налоги, как и вся налоговая система, являются мощным инструментом управления экономикой в условиях рынка. Использование налогов является одним из экономических методов управления и обеспечения взаимосвязи общегосударственных интересов с коммерческими 
интересами предпринимателей и организаций, независимо от их форм собственности, организационно-правовой формы и ведомственной подчиненности. При помощи налогов регулируется внешнеэкономическая, таможенная деятельность, включая привлечение иностранных инвестиций, формируются хозрасчетный доход и прибыль предприятия. С помощью налогов государство получает в свое распоряжение ресурсы, необходимые для выполнения своих функций в социально-экономической сфере. За счет налогов финансируются расходы по социальному обеспечению, которые изменяют распределение доходов. Система налогового обложения определяет конечное распределение доходов между людьми.

Создавая стабильное высокоразвитое общество с рыночной экономикой, государство должно иметь адекватную и эффективную систему налогов и налогообложения, которая отвечала бы общественным интересам, формировала благоприятные условия для хозяйственной деятельности, обеспечивала развитие и безопасность государства, учитывала интересы отдельных групп населения [1, 3-5].

Несовершенства налогового инструментария является причиной возникновения таких проблем, как:

- $\quad$ высокий уровень бедности в отдельных регионах;

- дифференциация доходов населения.

Осуществление налогового менеджмента направлено на решение социально-экономических проблем, а также на достижение целей устойчивого развития (ЦУР) государства. Налоговый менеджмент обеспечивает построение эффективного налогообложения на всех уровнях, и поэтому практика его применения имеет высокую значимость, особенно в период цикличного обострения социально-экономических проблем.

Mamериальи и методы / Materials and methods. Теоретическую и методологическую основу исследования составляют результаты фундаментальных работ по экономической теории и прикладных работ по налоговому менеджменту; основные положения стратегического менеджмента, теории управления и теории систем; элементы системного подхода, теории управления производством; методы экономического анализа; прогнозирование и моделирование экономических процессов.

Основным методом исследования является научная абстракция как выделение наиболее значимых сторон исследуемого явления и уход от всего случайного и второстепенного. Научная абстракция применительно к объекту исследования позволит рассмотреть инновационный налоговый менеджмент в наиболее общем виде, вскрыть внутренние закономерности и показать его основные тенденции.

Достижение поставленной цели и решение обозначенных задач возможны при условии использования в процессе исследования и оценки его результатов следующих общенаучных методов:

- дедукция и индукция - позволят повысить качество работ за счет опоры на общенаучные принципы проведения исследования теоретических основ, принципов и инструментов и обеспечения логики исследования;

- $\quad$ анализ и синтез - обеспечат построение целостной, научно-обоснованной концепции проведения анализа;

- аналогия - данный метод позволяет переносить ранее изученные задачи из одной области исследования в другую, получая при этом новые результаты, в частности, с его помощью удастся оценить возможности использования лучшего мирового опыта инновационного менеджмента;

- $\quad$ наблюдение - универсальный способ организации совместной деятельности и оценки эффекта управленческих решений. Он может быть применен на всех этапах осушествления научного исследования, в особенности при проведении этапа статистического наблюдения;

- $\quad$ обобщение - будет применено при подготовке отчета о проделанной работе. 
Среди частнонаучных методов познания в исследовании планируется использовать компаративный метод и метод экономико-математического моделирования.

К основным приоритетным задачам налогового менеджмента можно отнести:

- ликвидация бедности в отдельных субъектах РФ;

- сокращение уровня дифференциации доходов населения.

Pезультаты и обсуждение / Results and discussion. Высокий уровень бедности является одной из острых проблем современной России. Доля населения с доходами ниже величины прожиточного минимума в отдельных регионах достигает значения 40,5 \% (Республика Тыва, Сибирский федеральный округ). В целом по округам Российской Федерации значение этого показателя варьируется от $11,2 \%$ и до 20,2 \% (рис. 1) [2].

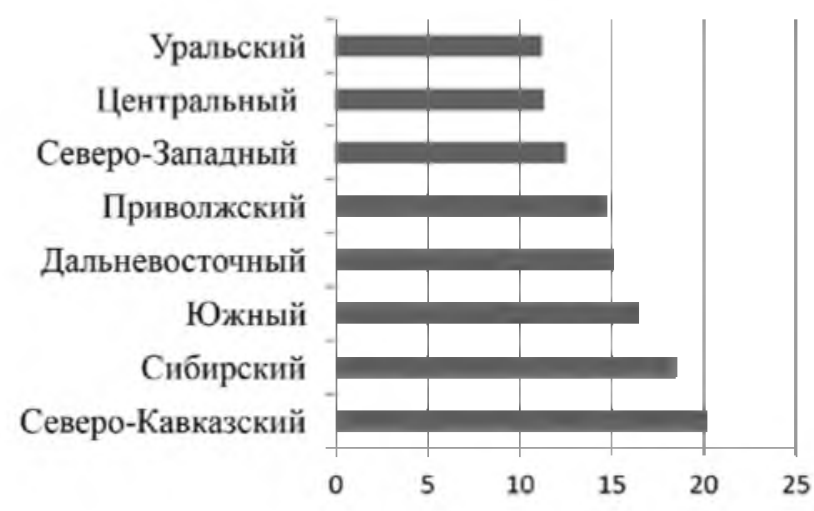

Рис. 1. Доля населения с доходами ниже прожиточного минимума в разрезе округов РФ, 2017 г.

В целях сокращения бедности могут быть применены следующие инструменты налогового менеджмента:

- необлагаемый налоговый минимум (создание порогового уровня доходов, при котором малообеспеченные слои населения будут освобождены от уплаты налогов, позволит минимизировать нагрузку);

- $\quad$ налоговые льготы (в современных условиях система налоговых вычетов и льгот требует пересмотрения: например, размер стандартных налоговых вычетов не изменялся с 2012 года, несмотря на то что величина прожиточного минимума увеличилась на $60,5 \%$. Более того, до 2012 года каждому налогоплательщику предоставлялся вычет на самого себя в размере 400 рублей. Удельный вес налогового вычета в общем объёме доходов сократился с $21,5 \%$ до 13,4 \% (таблица 1). Безусловно, значение налогового вычета нивелировано и требует индексации.

Таблица 1

Динамика удельного веса стандартного вычета в общем объеме доходов

\begin{tabular}{|c|c|c|c|}
\hline Год & Размер вычета руб. & $\begin{array}{c}\text { Размер прожит. минимума, } \\
\text { руб. }\end{array}$ & $\begin{array}{c}\text { Удельный вес вычета } \\
\text { в об̆ем объеме доходов, \%* }\end{array}$ \\
\hline 2011 & 1000 & 6369 & 15,7 \\
\hline 2012 & 1400 & 6510 & 21,5 \\
\hline 2014 & 1400 & 8050 & 17,4 \\
\hline 2016 & 1400 & 9828 & 14,2 \\
\hline 2018 & 1400 & 10451 & 13,4 \\
\hline
\end{tabular}

* за объем доходов в расчетах принимается минимальный размер оплаты труда 
Неравенство в распределении доходов является важным экономическим показателем и характеристикой социального благополучия или неблагополучия в обществе. После перехода к рыночной экономике неравенство росло высокими темпами, в конце 90-х гг. темп роста социального неравенства снизился. Основной проблемой является тот факт, что в период быстрого экономического подъема (до кризиса 2008 года) структура социального неравенства не изменилась, а впоследствии неравенство увеличилось, кризис 2008-2010 гг. не внес никаких заметных изменений в эту тенденцию (таблица 2) [1].

Таблица 2

Значение показателей дифференциации населения по доходам в динамике

\begin{tabular}{|c|c|c|c|c|c|}
\hline Год & $\begin{array}{c}\text { Децильньй } \\
\text { коэффициетт }\end{array}$ & $\begin{array}{c}\text { Коэффициент } \\
\text { Джини }\end{array}$ & Год & $\begin{array}{c}\text { Децильньй } \\
\text { коэффициент }\end{array}$ & $\begin{array}{c}\text { Коэффициент } \\
\text { Джини }\end{array}$ \\
\hline 1998 & 13,8 & 0,394 & 2008 & 16,6 & 0,421 \\
\hline 1999 & 14,1 & 0,400 & 2010 & 16,6 & 0,421 \\
\hline 2000 & 13,9 & 0,395 & 2012 & 16,4 & 0,420 \\
\hline 2002 & 14,0 & 0,397 & 2014 & 16,0 & 0,416 \\
\hline 2004 & 15,2 & 0,409 & 2015 & 15,7 & 0,413 \\
\hline 2006 & 15,9 & 0,415 & 2016 & 15,5 & 0,412 \\
\hline 2007 & 16,7 & 0,422 & 2018 & 15,3 & 0,411 \\
\hline
\end{tabular}

Тенденция увеличения дифференциации населения по доходам преобладает, и на сегодняшний день введение прогрессивной шкалы в сложившейся ситуации просто необходимо во избежание приближения России к странам третьего мира. Однако стоит учитывать и отрицательные последствия перехода:

- повышение налоговой нагрузки может привести к сокрытию своих доходов высокообеспеченного населения (к уклонению от уплаты налогов). «В целом неуплата налогов несет в себе высокую обшественную опасность, выражающуюся в причинении существенного ущерба государству. Недостаточное количество денежных средств в бюджете лишает правительство и субъекты Российской Федерации одного из наиболее важных инструментов управления, отрицательно влияет на социальную сферу, провоцирует социальную напряженность и политическую нестабильность» [1];

- увеличение издержек на налоговое администрирование; усложнение процесса исчисления и уплаты данного налога (налогоплательщику придется самостоятельно декларировать свои доходы).

Заключение / Conclusion. Достижение цели сокращения неравенства населения с помошью фискальных инструментов требует решения следуюших задач: расширение спектра налоговых льгот в целях сокращения налоговой нагрузки на малообеспеченные слои населения; применение прогрессивной системы налогообложения. В государствах с прогрессивной шкалой налогообложения уровень собираемости налога достаточно высок. Федеральный бюджет этих государств в основном обеспечивается налогами, взимаемыми с граждан, получающих высокие доходы, 4-10\% граждан обеспечивает до 40-50 \% налоговых поступлений по данному налогу в бюджет страны. 


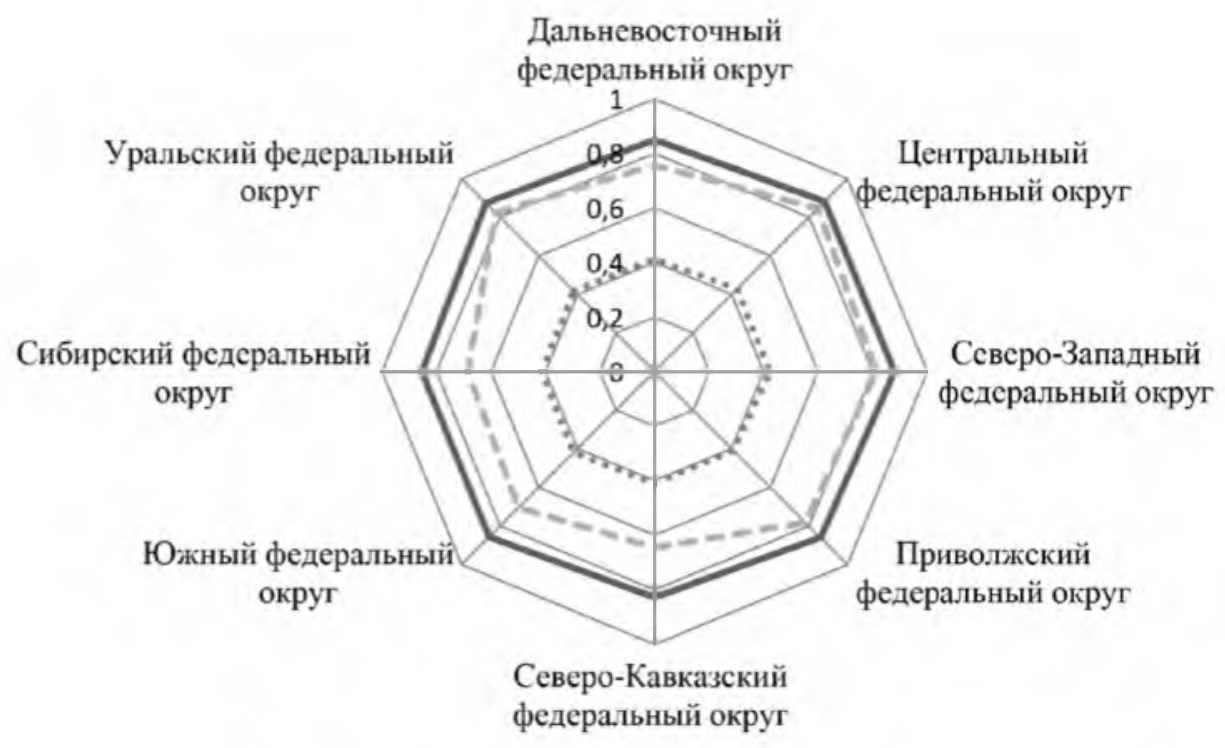

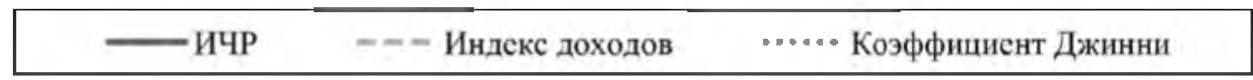

Рис. 2. Показатели социального-экономического развития в разрезе округов РФ

Среднее значение индекса человеческого развития и индекса доходов в разрезе округов различается несущественно (рис. 2). Однако же значение данных показателей во многих регионах соответствует странам третьего мира, демонстрируется сильный разрыв между самыми благополучными и депрессивными регионами. В результате реализации предложенных автором направлений представляется возможным нивелировать социально-экономическое неравенство на мезоуровне.

\section{ЛИТЕРАТУРА И ИНТЕРНЕТ-РЕСУРСЫ}

1. Григорьева Л. М., Бобылева С. Н. Доклад о человеческом развитии в Российской Федерации за 2016 год. М.: Аналитический центр при Правительстве Российской Федерации, 2016. 298 с.

2. Суринов А. Е. Россия в цифрах - 2017: крат. стат. сб. / Росстат. М., 2017. 511 с.

3. Тимошенко Н. В. Социальное неравенство в России: экономический анализ причин возникновения // Вестник Адыгейского государственного университета. 2017. № 5. С. 225-230.

4. Тюрина Ю. Г. Налоговые реформы в системе экономических преобразований: теоретический аспект// Инновационное развитие экономики. 2016. № 33. С. 138-141.

5. Устинова Е. Л. Основные направления налоговой политики РФ на современном этапе // Общество, экономика и устойчивое развитие: междисциплинарные исследования: сборник научных трудов по материалам I Международной научно-практической конференции, 2 марта. Новосибирск: Профессиональная наука. 2018. С. 16-20.

\section{REFERENCES AND INTERNET RESOURCES}

1. Grigor'eva L. M., Bobyleva S.N. Doklad o chelovecheskom razvitii v Rossijskoj Federacii za 2016 god (Report on human development in the Russian Federation for 2016). M.: Analiticheskij centr pri Pravitel'stve Rossijskoj Federacii, 2016. 298 s.

2. Surinov A. E. Rossija v cifrah - 2017 (Russia in numbers - 2017): krat. stat. sb. / Rosstat. M., 2017.511 p.

3. Timoshenko N. V. Social'noe neravenstvo v Rossii: jekonomicheskij analiz prichin vozniknovenija (Social inequality in Russia: an economic analysis of the causes) // Vestnik Adygejskogo gosudarstvennogo universiteta. 2017. No. 5. S. 225-230. 
4. Tjurina Ju. G. Nalogovye reformy v sisteme jekonomicheskih preobrazovanij: teoreticheskij aspect (Tax reforms in the system of economic transformations: a theoretical aspect) // Innovacionnoe razvitie jekonomiki. 2016. No. 33. S. 138-141.

5. Ustinova E. L. Osnovnye napravlenija nalogovoj politiki RF na sovremennom jetape (The main directions of the tax policy of the Russian Federation at the present stage) // Obshhestvo, jekonomika i ustojchivoe razvitie: mezhdisciplinarnye issledovanija: sbornik nauchnyh trudov po materialam I Mezhdunarodnoj nauchno-prakticheskoj konferencii, 2 marta 2018. Novosibirsk: Professional'naja nauka, 2018, S. 16-20.

\section{СВЕДЕНИЯ ОБ АВТОРАХ}

Кулаговская Татьяна Анатольевна, доктор экономических наук, профессор, заведующий кафедрой налоговой политики и таможенного дела, Института экономики и управления, Федеральное государственное автономное образовательное учреждение высшего образования «Северо-Кавказский федеральный университет. E-mail: kulagovskaya@mail.ru

Билоус Екатерина Константиновна, студентка 1 курса магистратуры, направления подготовки 38.04 .08 Финансы и кредит, направленности «Налоговый менеджмент», Института экономики и управления, Федеральное государственное автономное образовательное учреждение высшего образования «Северо-Кавказский федеральный университет». E-mail: ketrina-b@mail.ru

\section{INFORMATION ABOUT THE AUTHORS}

Tatyana Kulagovskaya, Doctor of Economics, Professor, head of the Department of Tax Policy and Customs Affairs, Institute of Economics and Management, Federal state Autonomous educational institution of higher education «North-Caucasus Federal University». E-mail: kulagovskaya@,mail.ru

Ekaterina Bilous, student 1st year of magistracy, field of study, 38.04.08 Finance and Credit, «Tax Management», Institute of Economics and Management, Federal state Autonomous educational institution of higher education «North-Caucasus Federal University». E-mail: ketrina-b@mail.ru 